\title{
Retinoschisis and macular detachment associated with acquired enlarged optic disc cup
}

This article was published in the following Dove Press journal:

Clinical Ophthalmology

19 March 2012

Number of times this article has been viewed

\section{María Moreno-López Julio José González-López Elena Jarrín Josefina Bertrand \\ Ophthalmology Department, Hospital Universitario Ramón y Cajal, Madrid, Spain}

\begin{abstract}
We describe a case of maculopathy consisting of macular retinoschisis and serous macular detachment occurring in a patient with an acquired enlarged optic disc cup, similar to the maculopathy observed in congenital optic nerve abnormalities, mainly optic nerve pits and colobomas, without vitreomacular traction nor angiographic leak. Pars plana vitrectomy with argon laser endophotocoagulation and gas tamponade was found to be useful. Traction from membranes covering deep optic disc cups may create small retinal dehiscences, as described in congenital optic nerve abnormalities, which will enable the liquefied vitreous to pass, leading to retinoschisis with or without associated neurosensory detachment. Vitrectomy, photocoagulation, and gas tamponade may be a useful therapy for this entity.
\end{abstract}

Keywords: glaucoma, macular detachment, macular surgery, optic disc, retinoschisis

\section{Introduction}

Macular retinoschisis and serous macular detachment have been broadly described in the presence of congenital optic nerve abnormalities, mainly optic nerve pits and colobomas. ${ }^{1,2}$

Recently, three papers have described a similar maculopathy in association with an acquired optic disc cup enlargement in glaucoma patients. ${ }^{3-5}$ The purpose of this paper is to present a case of maculopathy secondary to an enlarged optic disc cup, to show the usefulness of optic coherence tomography in the diagnosis of this entity, to discuss its pathogenesis and, finally, to propose a surgical approach.

\section{Case report}

A 64-year-old, nonhypertensive, emmetropic woman without any relevant past medical history presented at our emergency department due to a sudden loss of vision in her right eye. This was her only useful eye, because she presented a long history of low vision of unknown origin in her left eye (counting fingers at $20 \mathrm{~cm}$ ), for which she had never requested medical attention. Visual acuity in her right eye was 20/30. Anterior segment examination was normal in both eyes. Intraocular pressure was $30 \mathrm{mmHg}$ in both eyes. Right eye funduscopy showed a central retinal vein occlusion, and a cup/disc ratio of 0.7 (Figure 1A). Left eye funduscopy showed a cup/disc ratio of 0.8 without any other abnormality in the optic nerve head, and a serous macular detachment (Figure 1B). Retinal fluorescein angiography showed a choroidal silence and signs of Stargardt disease in both eyes (Figure 1D and E). Left eye retinal fluorescein angiography failed to show any leakage (Figure 1E). Optic coherence tomography
González-López

Sevicio de Oftalmología. Hospital

Universitario Ramón y Cajal, Carretera

de Colmenar, 28034 Madrid, Spain

$\mathrm{Tel}+3468653$ 909l

$\mathrm{Fax}+349 \quad 14338099$

Email juliojose.gonzalez@live.com 

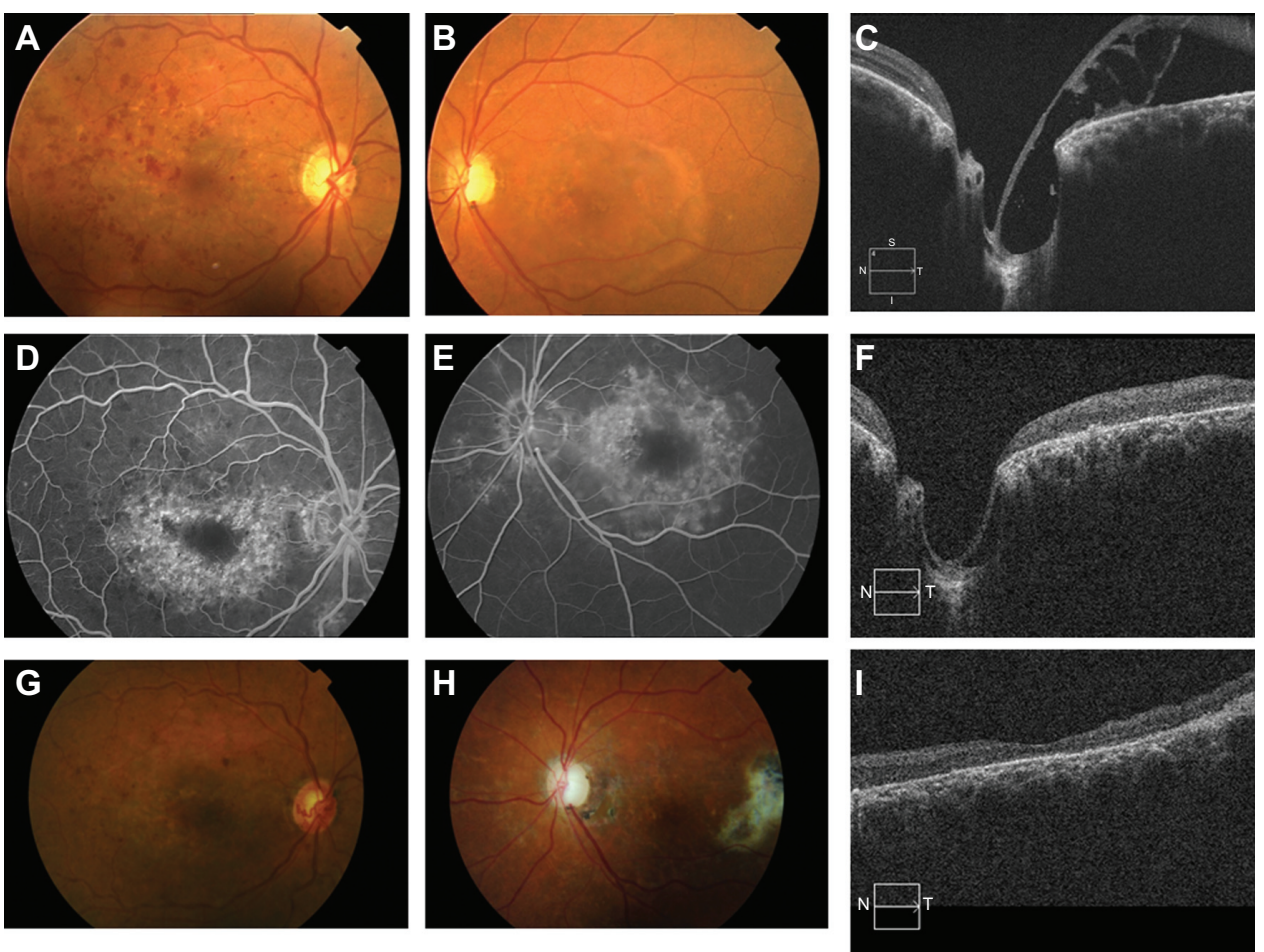

Figure I Macular schisis and detachment associated with presumed acquired optic nerve head cupping. (A) Right eye fundus photograph at presentation, showing tortuous veins and multiple retinal hemorrhages compatible with central retinal vein occlusion. (B) Left eye fundus photograph showing schisis and detachment in the macula of the left eye associated with an enlarged optic disc cup at presentation. (C) Left eye optic disc optical coherence tomography at the black line in $\mathbf{B}$ showing a communication between the enlarged optic disc cup and the macular retinoschisis and neurosensory detachment at presentation. (D) Right eye fluorescein angiography showing central retinal vein occlusion and Stargardt disease at presentation. (E) Left eye fluorescein angiography showing absence of leak and Stargardt disease at presentation. (F) Left eye optic disc optical coherence tomography at the black line in $\mathrm{H}$, showing closure of the communication between the enlarged optic disc cup and macular retinoschisis six months after surgery. (G) Right eye fundus photograph showing evolution of central retinal vein occlusion six months after the surgery day. Macular edema improved after three-monthly intravitreal bevacizumab injections. (H) Left eye fundus photograph of the left eye showing improved schisis and detachment, optic disc pallor, and a subretinal fibrosis temporal to fovea corresponding with the retinotomy site, six months after surgery. (I) Left eye macular optical coherence tomography centered in the fovea (dotted line in $\mathbf{H}$ ), obtained six months after surgery, showing an improvement in the subretinal and intraretinal fluid.

showed a macular detachment in her left eye communicating with an enlarged optic disc cup, with no evidence of vitreomacular traction (Figure 1C). She was diagnosed as having primary open-angle glaucoma in both eyes, for which she started treatment with latanoprost, and was also diagnosed with central retinal vein occlusion in her right eye. Genetic testing for Stargardt disease was performed, but the results were negative.

Surgery was recommended in order to resolve the serous macular detachment in her left eye. A 23 gauge pars plana vitrectomy was performed. The posterior hyaloid was found to be firmly attached to the temporal margin of the optic disc. Subretinal fluid drainage was attempted through a temporal retinotomy. Before the retina was reapplied, three rows of endolaser photocoagulation burns were applied to the temporal margin of the optic disc. The aim of this technique is to treat the retinal pigment epithelium only, while avoiding damage to the neurosensory retina. C3F8 12\% was used as endotamponade. Optic coherence tomography performed six months after surgery showed resolution of the macular retinoschisis, and persistence of the membrane over the optic disc cup (Figure 1F, H, and I). However, visual acuity decreased to hand motion in her left eye six months after surgery, and papillary atrophy developed in spite of good intraocular pressure control (all measures inferior to $17 \mathrm{mmHg}$ ) with latanoprost (Figure $1 \mathrm{H}$ ). This may be due to the progression of her previous glaucomatous damage, a common course in advanced glaucoma patients even when their intraocular pressure is normalized; to foveal atrophy because of the chronicity of the retinoschisis and macular detachment; to high intraoperative intraocular pressure; to endolaser photocoagulation burns; or to intraocular pressure elevation due to endotamponade.

\section{Discussion}

Macular retinoschisis with or without macular neurosensory detachment has been described in congenital optic nerve abnormalities. Gass ${ }^{6}$ and other authors ${ }^{7}$ have suggested the fluid to be of cerebrospinal origin, which would gain access from the subarachnoid space and through the optic nerve 
defect to the subretinal space. The more accepted hypothesis today is Sugar's theory, ie, a liquefied vitreous passes through an optic nerve defect (pit) and dissects the retinal layers, after which it migrates into the subretinal space, causing a neurosensory retinal detachment. ${ }^{8}$

Brown et al observed that more than three quarters of patients with macular detachment associated with optic nerve pits developed posterior vitreous detachment, while patients with optic nerve pits alone did not develop posterior vitreous detachment. ${ }^{9}$ Hence, posterior vitreous traction may play a role in the pathogenesis of maculopathy. In our patient, there were no previous ophthalmic reports documenting the presence of a previous vitreous detachment. Recently, a similar maculopathy associated with an enlarged optic disc cup has been described. ${ }^{3-5}$ An increase in intraocular pressure ${ }^{2}$ or structural damage to the optic disc due to ganglion cell loss may facilitate the flow of liquefied vitreous through a small dehiscence in the inner part of an enlarged optic disc cup.

Other causes of exudative macular detachment without angiographic leakage include hyperviscosity syndromes, like Waldenström macroglobulinemia, multiple myeloma, endocarditis, leukemia, ischemic microvasculopathies like diabetes mellitus and hypertension, and even intracranial trauma (eg, shaken baby syndrome). ${ }^{10}$ In contrast, macular detachment in exudative age-related macular degeneration, Vogt-Koyanagi-Harada disease, central serous retinopathy, malignant hypertension, posterior scleritis, and sympathetic ophthalmia, among other conditions, will show one or more pinpoint leaks in the retinal pigment epithelium on fluorescein angiography. ${ }^{10}$

Optic coherence tomography imaging has shown the presence of membranes spanning optic disc pits. ${ }^{11}$ Similar membranes have been described in patients with large, acquired optic nerve cupping. ${ }^{4,5}$ It has been postulated that tiny holes in these membranes covering the optic nerve defect may allow the entry of fluid from the vitreous cavity, initially causing retinoschisis and later on a neurosensory macular detachment. ${ }^{5}$ In fact, Pilon et a ${ }^{12}$ described a patient with a macular detachment associated with a fractured inner limiting membrane over a complete excavation of the optic disc cup.

In the case presented here, the only optic nerve abnormality observed associated with the presence of retinoschisis was an enlarged optic disc cup confirmed by optic coherence tomography imaging and associated with a membrane covering the optic disc cup. The patient did not have any other signs or symptoms of systemic disease that may have accounted for the exudative macular detachments. Additionally, in these conditions, macular detachments are usually bilateral and other signs are present on funduscopy, like Roth spots or turbid subretinal fluid from hyperviscosity syndromes or leukemia. ${ }^{10}$ In our case, optic coherence tomography clearly showed a communication between the deep optic disc cup and the schisis. The presence of a membrane over the optic disc cup shown in the optic coherence tomography of this eye is highly reminiscent of the membranes described over the optic nerve pits. ${ }^{11}$ In the series by Doyle et al,,${ }^{11}$ the membrane was present in three of five eyes without maculopathy, and was absent in the three eyes with maculopathy. However, in our case, the membrane can be seen in an eye with retinoschisis and macular detachment.

Even though there is no universally accepted treatment for optic disc pit maculopathy, several surgical techniques have been attempted. Vitrectomy has been shown to be useful to release tractions. Intraocular gas tamponade followed by face-down positioning facilitates macular reattachment. ${ }^{13}$ Several rows of laser photocoagulation burns between the retinal detachment and the optic nerve may close the communication and stop fluid flow.

We hypothesize that mechanical tractions exerted on the retina from membranes covering the optic disc cup may create small retinal dehiscences in acquired cupped optic discs, as described in congenital optic nerve abnormalities, which will enable the liquefied vitreous to enter the intraretinal or subretinal space. Spontaneous release of tractions may lead to the closure of these communications, as described after posterior vitreous detachment in macular detachment associated with optic nerve pits. ${ }^{9}$ Structural damage to retinal layers producing intraretinal degeneration due to chronicity may perpetuate the intraretinal cyst.

We believe that cases of macular retinoschisis or detachments in glaucoma patients may go undetected or be misdiagnosed as cystoid macular edema or other retinal or choroidal diseases. The common use of optic coherence tomography imaging has made possible the diagnosis of this syndrome.

\section{Disclosure}

The authors declare no conflicts of interest relevant to this article. No financial support was received for this submission.

\section{References}

1. Sobol WM, Boldi CF, Folk JC, Weingeist TA. Long-term visual outcome in patients with optic nerve pit and serous retinal detachment of the macula. Ophthalmology. 1990;97:1539-1542.

2. Yamakiri K, Uemura A, Sakamoto T. Retinal detachment caused by a slit-like break within the excavated disc in morning glory syndrome. Retina. 2004;24:65-653. 
3. Farjad H, BesadaE, Frauens BJ. Peripapillary schisis with serous detachment in advanced glaucoma. Optom Vis Sci. 2010;87:E205-E217.

4. Kahook MY, Noecker RJ, Ishikawa H, et al. Peripapillary schisis in glaucoma patients with narrow angles and increased intraocular pressure. Am J Ophthalmol. 2007;143:697-699.

5. Zumbro DS, Jampol LM, Folk JC, Olivier MMG, Anderson-Nelson S. Macular schisis and detachment associated with presumed acquired enlarged optic nerve head cups. Am J Ophthalmol. 2007;144:70-74.

6. Gass JDM. Serous detachment of the macula secondary to congenital pit of the optic nerve head. Am J Ophthalmol. 1969;67:821-841.

7. Irvine AR, Crawford JB, Sullivan JH. The pathogenesis of retinal detachment with morning glory disk and optic pit. Retina. 1986;6:146-150.

8. Sugar HS. An explanation for the acquired macular pathology associated with congenital pits of the optic disc. Am J Ophthalmol. 1964;57:833-835.
9. Brown GC, Shields JA, Goldberg RE. Congenital pits of the optic nerve head. II. Clinical studies in humans. Ophthalmology. 1980;87:51-65.

10. Bui AT, Rosen BS, Roe RH, Kokame GT. Diagnostic and therapeutic challenges. Retina. 2010;30:1744-1748.

11. Doyle E, Trivedi D, Good P, Scott RA, Kirkby GR. High-resolution optical coherence tomography demonstration of membranes spanning optic disc pits and colobomas. Br J Ophthalmol. 2009;93:360-365.

12. Pilon A, Newman T, Messner LV. Neurosensory detachment arising from a fractured inner-limiting membrane secondary to chronically elevated intraocular pressure. Optom Vis Sci. 2006;83:415-420.

13. Cox MS, Witherspoon CD, Morris RE, Flynn HW. Evolving techniques in the treatment of macular detachment caused by optic nerve pits. Ophthalmology. 1988;95:889-896.
Clinical Ophthalmology

\section{Publish your work in this journal}

Clinical Ophthalmology is an international, peer-reviewed journal covering all subspecialties within ophthalmology. Key topics include: Optometry; Visual science; Pharmacology and drug therapy in eye diseases; Basic Sciences; Primary and Secondary eye care; Patient Safety and Quality of Care Improvements. This journal is indexed on

\footnotetext{
Submit your manuscript here: http://www.dovepress.com/clinical-ophthalmology-journal
}

\section{Dovepress}

PubMed Central and CAS, and is the official journal of The Society of Clinical Ophthalmology (SCO). The manuscript management system is completely online and includes a very quick and fair peer-review system, which is all easy to use. Visit http://www.dovepress.com/ testimonials.php to read real quotes from published authors. 